\title{
Detecção de Mycoplasma genitalium, M. fermentans e M. penetrans em pacientes com sintomas de uretrite e em indivíduos infectados pelo HIV-1 no Brasil
}

\author{
Detection of Mycoplasma genitalium, M. fermentans and M. penetrans in patients with symptoms of urethritis and \\ in HIV-1 infected persons in Brazil
}

Caio Mauricio Mendes de Cordova'

Regina Ayr Flório da Cunha²

\begin{tabular}{l|l}
\multicolumn{1}{c|}{ Unitermos } & resumo \\
$\begin{array}{l}\text { M. penetrans } \\
\text { M. fermentans }\end{array}$ & $\begin{array}{l}\text { Neste trabalho investigamos a prevalência de três espécies de micoplasma recém- } \\
\text { identificadas como patógenos humanos, M. genitalium, implicado em casos de uretrite não- } \\
\text { gonocócica, e M. fermentans e M. penetrans, isolados de pacientes imunodeprimidos, e das } \\
\text { HIV }\end{array}$ \\
$\begin{array}{l}\text { Pretrite } \\
\text { duas espécies mais freqüentes no trato geniturinário, M. hominis e U. urealyticum. Foram } \\
\text { estudados } 110 \text { pacientes com sintomas de uretrite (grupo A) e } 106 \text { indivíduos infectados pelo } \\
\text { HIV-1 (grupo B). M. genitalium foi detectado em 10,9\% das amostras de raspado uretral do } \\
\text { grupo A, e em 1,9\% das amostras de raspado uretral e 0,9\% das amostras de urina do grupo } \\
\text { B. M. fermentans foi detectado em 0,9\% e 5,7\% das amostras de raspado uretral dos grupos } \\
\text { A e B, respectivamente. M. penetrans foi detectado em 6,6\% das amostras de urina somente } \\
\text { do grupo B. M. hominis e U. urealyticum tiveram taxas de infecção de 0,9\% e 14,5\% no grupo } \\
\text { A, e de 7,5\% e 18,9\% no grupo B, respectivamente. A relevante prevalência da infecção por } \\
\text { estas novas espécies, em comparação aos micoplasmas mais conhecidos do trato urogenital, } \\
\text { sugere que a magnitude do papel destes microrganismos no âmbito das doenças sexualmen- } \\
\text { te transmissíveis (DST) e da infecção pelo HIV pode estar sendo subestimada em nossa } \\
\text { população. }\end{array}$
\end{tabular}

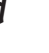




\section{Introdução}

Por muitos anos, as espécies de micoplasma reconhecidas como patógenos humanos do trato geniturinário (TGU) estavam restritas a Mycoplasma hominis e Ureaplasma urealyticum (41), e, no trato respiratório, a M. pneumoniae (4). Os micoplasmas pertencem à classe Mollicutes, que tem como principais características a ausência de parede celular e o genoma reduzido, e são responsáveis por uma série de doenças no homem, em plantas e em animais (33). Nas duas últimas décadas, esta situação começou a mudar, com o isolamento de uma nova espécie, $M$. genitalium, do trato urogenital de homens com uretrite não-gonocócica (44). M. genitalium foi detectado pela reação em cadeia da polimerase (PCR), mais freqüentemente de amostras uretrais de homens com uretrite nãogonocócica, em comparação com homens sem estes sintomas, sendo os anticorpos anti-M. genitalium mais freqüentemente detectados nos soros de homens com PCR positiva para este micoplasma do que nos soros de homens com PCR negativa (42). O DNA de M. genitalium foi também detectado por PCR em amostras uretrais de homens com doença persistente ou recorrente seguida por um ataque agudo da doença $(42,43)$. Estes dados subsidiam o papel de $M$. genitalium como um dos agentes etiológicos da uretrite não-gonocócica.

No final da década de $80, M$. fermentans, uma espécie isolada do trato urogenital no início dos anos 50 (34), mas considerada infreqüente neste sítio, foi isolado de lesões de sarcoma de Kaposi de um paciente com síndrome de imunodeficiência adquirida (Aids) $(23,26)$, e finalmente classificado como a cepa incognitus de $M$. fermentans $(25,36)$. Outros isolados de pacientes infectados pelo HIV se sucederam a partir de células mononucleares do sangue periférico (PBMC) (22) e de amostras de urina (12), o que demonstrou $M$. fermentans como o primeiro micoplasma invasivo no homem. Estes dados, junto com as observações in vitro de que M. fermentans e outros micoplasmas podem induzir a replicação do HIV (7), levaram pela primeira vez à hipótese de que estes microrganismos podem ter um papel no desenvolvimento da Aids (30). M. fermentans foi detectado também em pacientes com doenças respiratórias severas, algumas vezes fatais, especialmente em indivíduos imunodeprimidos, nos quais pode ainda ser responsável por doenças mais invasivas, como nefropatias $(2,27)$.

M. penetrans é a espécie de micoplasma mais recentemente identificada infectando o homem, tendo sido também isolado da urina de pacientes com Aids $(24,25)$. Seu isolamento de indivíduos infectados pelo HIV e sua alta soroprevalência nestes pacientes em comparação a indivíduos HIV-negativos $(16,17,45,48,49)$, juntamente com suas propriedades in vitro de potente ativador do sistema imune $(18,37)$ e de estimulador da expressão de genes do HIV LTR-dependentes (31), colocam $M$. penetrans como o melhor candidato a eventual co-fator do HIV no desenvolvimento da Aids, segundo Montagnier e Blanchard $(6,30)$. Mais recentemente foi sugerida uma associação entre infecção ativa por $M$. penetrans e progressão da Aids (17).

O isolamento de novas espécies de micoplasma e o meIhor entendimento de espécies já conhecidas e que vêm emergindo provavelmente como agentes oportunistas têm aberto novos horizontes na micoplasmologia humana. Deste modo, foi objetivo do presente trabalho investigar a presença destes novos patógenos, $M$. genitalium, $M$. fermentans e $M$. penetrans, em nossa população e sua freqüência no âmbito da infecção pelo HIV e das doenças sexualmente transmissíveis (DST), mais especificamente das uretrites nãogonocócicas, e de $M$. hominis e $U$. urealyticum, micoplasmas já caracterizados como patógenos do trato urogenital.

\section{Material e métodos}

\section{Pacientes e amostras}

\section{Grupo A}

Foi constituído por 110 homens adultos com queixa e sintomas de uretrite, com sorologia negativa para o HIV. Pacientes sob antibioticoterapia foram excluídos do estudo. As amostras foram coletadas mediante consentimento pós-informado.

\section{Grupo B}

Foi constituído por 106 homens adultos infectados pelo HIV-1, sem sintomas clínicos de uretrite. A determinação dos níveis de células T CD4+ pôde ser obtida de 58 pacientes $(54,7 \%)$. Seis $(10,3 \%)$ apresentavam níveis de células T CD4+ abaixo de 50/ $\mathrm{mm}^{3} ; 26(44,8 \%)$ apresentavam níveis entre 50 e $250 / \mathrm{mm}^{3} ; 17$ (29,3\%), entre 250 e 500/ $\mathrm{mm}^{3}$; e nove $(15,5 \%)$, acima de $500 / \mathrm{mm}^{3}$. Pacientes com níveis de células T CD4+ iguais ou abaixo de $250 / \mathrm{mm}^{3}$ estavam recebendo terapia profilática preventiva. As amostras foram coletadas mediante consentimento pós-informado, com projeto aprovado pela Comissão de Ética do Hospital do Servidor Público Estadual de São Paulo. 


\section{Amostras}

Para a pesquisa de micoplasmas, amostras de raspado uretral foram colhidas e mantidas em $3 \mathrm{ml}$ de meio de transporte $A_{3 X B}$ modificado (39) a $4^{\circ} \mathrm{C}$ por no máximo duas horas até o processamento. Amostras de primeiro jato urinário (cerca de $10 \mathrm{ml}$ ) foram concentradas dez vezes por centrifugação e mantidas em $3 \mathrm{ml}$ de meio de transporte.

Para os pacientes do grupo A, a pesquisa de Chlamydia trachomatis foi realizada a partir de amostras de raspado uretral, utilizando-se o kit ChlamydiaZyme (Abbott Diagnostics, Abbottville, EUA), de acordo com as instruções do fabricante. A pesquisa de Trichomonas vaginalis foi realizada por exame microscópico direto, a partir de amostras de primeiro jato urinário, e a cultura bacteriana foi realizada a partir de amostras de secreção uretral, de acordo com os procedimentos tradicionais de rotina.

\section{Cultura de micoplasmas}

De cada amostra, 0,1 $\mathrm{ml}$ foi inoculado em meio sólido A7, e 0,5 ml em tubos contendo $2 \mathrm{ml}$ de meio líquido U10, arginina, ou SP-4 (40). A partir destes tubos ainda foram feitas duas diluições seriadas de razão 10, resultando em cultura das amostras diluídas 1:5, 1:50 e 1:500, para evitar a interferência de inibidores de crescimento, como antibióticos, anticorpos e mesmo outras bactérias, que possam eventualmente estar presentes na amostra. A omissão desta diluição é uma das razões pelas quais alguns laboratórios têm dificuldade no isolamento dos micoplasmas, pois freqüentemente a amostra não-diluída é negativa, enquanto as diluições seguintes apresentam crescimento (47). As culturas foram incubadas a $37^{\circ} \mathrm{C}$, com $2 \%$ a $3 \%$ de $\mathrm{CO}_{2}$, por até duas semanas, com exceção das amostras inoculadas em meio SP-4, que foram incubadas em aerobiose por até quatro semanas. Na tentativa de isolamento de $M$. fermentans, tubos com meio SP-4 foram incubados em anaerobiose, utilizando-se o GasPack ${ }^{\circledR}$ System com gerador de anaerobiose AnaeroGen ${ }^{\mathrm{TM}}$ (Oxoid Ltd., Basingstoke, Hamshire, Inglaterra).

\section{Quantificação dos isolados}

A quantificação de $M$. hominis e $U$. urealyticum nas amostras de raspado uretral foi feita pela técnica de microtitulação, uma vez que esta metodologia está bem padronizada para este tipo de material (40). Em uma placa estéril de 96 cavidades, foram inoculados $30 \mathrm{ml}$ da amostra clínica em $270 \mathrm{ml}$ de meio de cultura, quer seja U10 para $U$. urealyticum ou arginina para $M$. hominis. Diluições seriadas de razão 10 foram feitas a partir da primeira cavidade. A maior diluição que apresentou mudança da cor do indicador de $\mathrm{pH}$ presente no meio de cultura representou o número de microrganismos na amostra, expresso em CCU (color changing units) por mililitro. São considerados significativos valores acima de $10^{3} \mathrm{CCU} / \mathrm{ml}$ para $\mathrm{M}$. hominis, e acima de $10^{4} \mathrm{CCU} / \mathrm{ml}$ para U. urealyticum (47).

\section{Detecção de micoplasmas por PCR}

\section{Preparação das amostras}

As amostras foram tratadas de acordo com o procedimento descrito por Barbeyrac et al. (3). Um mililitro de cada amostra foi centrifugado a $13.000 \times \mathrm{g}$, ressuspenso em $0,5 \mathrm{ml}$ de tampão de lise (Tris-HCl 10mM, EDTA $1 \mathrm{mM}$, Triton

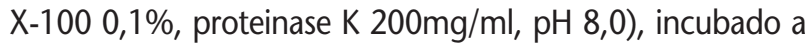
$56^{\circ} \mathrm{C}$ por $60 \mathrm{~min}$, e, em seguida, a $100^{\circ} \mathrm{C}$ por $10 \mathrm{~min}$. As amostras foram extraídas uma vez com fenol e uma vez com fenol/ clorofórmio/álcool isoamílico (25:24:1). O DNA foi precipitado com etanol e ressuspenso em $100 \mathrm{ml}$ de tampão TE (Tris-HCl 10mM, EDTA 1mM, pH 8,0).

\section{PCR}

Cada amostra foi inicialmente testada com um par de primers genérico para a classe Mollicutes: MGSO (5'tgcaccatctgtcactctgttaacctc-3') e GPO 1 (5'-actcctacgggaggcagccgta $\left.-3^{\prime}\right)$, que amplificam um fragmento de $716 \mathrm{bp}(46)$. Uma alíquota de $10 \mathrm{ml}$ da amostra foi amplificada em $50 \mathrm{ml}$ de reação contendo $5 \mathrm{ml}$ de Taq Reaction Buffer (Pharmacia Biotech, Uppsala, Suécia), 200mM de solução de dNTPs (Gibco BRL, Gaithersburg, MD, EUA), 30 pmoles de cada primer, e $1 U$ de Taq DNA Polymerase (Pharmacia Biotech). A amplificação foi feita com uma denaturação inicial a $95^{\circ} \mathrm{C}$ por $15 \mathrm{~min}$, seguida de 30 ciclos com denaturação a $95^{\circ} \mathrm{C}$ por $30 \mathrm{~s}$, anelamento dos primers a $58^{\circ} \mathrm{C}$ por $1 \mathrm{~min}$ e $30 \mathrm{~s}$, extensão a $72^{\circ} \mathrm{C}$ por $1 \mathrm{~min}$ e $30 \mathrm{~s}$, e uma etapa final de extensão a $72^{\circ} \mathrm{C}$ por $10 \mathrm{~min}$. Como controle interno de reação foi utilizado o plasmídeo $\mathrm{pBr}_{322}$, cuja amplificação de um fragmento de $965 \mathrm{bp}$ foi realizada utilizando-se os primers $\mathrm{pBr} 1$ ( 5 ' catctcgggcagcgttgggt-3') e pBr2 (5'-agcgacgcgagtcagtgagc$\left.3^{\prime}\right)$. Os produtos de PCR foram detectados por eletroforese em gel de agarose a 1\% com brometo de etídeo e visualizados sob luz UV.

Todos os pacientes que tiveram alguma amostra positiva com os primers genéricos foram também testados com primers específicos para $M$. penetrans: MYCPENETP (5'catgcaagtcggacgaagca-3') e MYCPENETN (5'-agcattcctcttcttacaa$\left.3^{\prime}\right)$, que amplificam um fragmento de 410bp (15); $M$. fermentans: Fer+ (5'-aagaagcgtttcttcgctgg-3') e Uni- 
(5'-taatcctgtttgctccccac-3'), que amplificam um fragmento de 588bp (14); e M. genitalium: Mge1 (5'-gaatgactctagcaggcaatggctg-3') e Mge2 (5'atttgccttttacaagttggct- $\left.3^{\prime}\right)$, que amplificam um fragmento de $809 \mathrm{bp}$ (38), nas mesmas condições descritas acima. Como controles positivos foram utilizadas a cepa GTU546A1 de M. penetrans, a cepa ATCC 33530 de $M$. genitalium e a cepa ATCC 19989 de M. fermentans.

\section{Análise estatística}

Os dados obtidos foram analisados pelo teste exato de Fisher.

\section{Resultados}

\section{Infecção por micoplasmas nos pacientes com sintomas de uretrite}

No grupo de pacientes com sintomas de uretrite (grupo $\mathrm{A}$ ), o isolamento de $U$. urealyticum por cultura foi obtido de amostras de 16 dentre os 110 pacientes (14,5\%). Destes isolados, $8,2 \%(9 / 110)$ estavam em concentrações $\geq 10^{4} \mathrm{CCU} / \mathrm{ml}$ e $6,3 \%$ (7/110) estavam em concentrações $<10^{4} \mathrm{CCU} / \mathrm{ml}$. M. hominis foi isolado de $0,9 \%(1 / 110)$ das amostras dos pacientes deste grupo, em concentração $\geq 10^{3} \mathrm{CCU} / \mathrm{ml}$. Não houve diferença na taxa de isolamento de micoplasmas quanto ao tipo de amostra utilizado, quer seja raspado uretral, quer seja primeiro jato urinário.

A detecção de micoplasmas por PCR com o uso de um par de primers genéricos teve uma positividade de 20,9\% (23/110) nas amostras de raspado uretral. Utilizando-se as amostras de urina, não foi observada reação positiva. Em todas as amostras testadas foi observada a reação positiva com o controle interno (plasmídeo $\mathrm{pBr}_{322}$ ), indicando a ausência de inibidores de amplificação. A negatividade da PCR nas amostras de urina com os primers genéricos, mesmo naquelas que tiveram cultura positiva, provavelmente deve-se a uma questão de sensibilidade. Considerando que os micoplasmas são microrganismos que colonizam o trato geniturinário aderidos às células epiteliais, sua detecção por esta reação pode ser negativa em amostras de primeiro jato de urina. Entretanto isto pode não ocorrer nas amostras de raspado uretral obtidas do mesmo paciente, cuja coleta produz uma quantidade maior de material celular. Por outro lado, reações com primers específicos para uma determinada espécie de micoplasma não apresentam este problema, por terem uma sensibilidade adequada. De fato, com o uso de primers específicos para as espécies pesquisadas, $M$ genitalium foi detectado em 10,9\% (12/110) das amostras de urina dos pacientes deste grupo que apresentaram PCR positiva com os primers genéricos. Excluindo-se os pacientes com resultado positivo para $N$. gonorrhoeae e C. trachomatis, M. genitalium foi responsável por 18,9\% (10/53) dos casos de uretrite. Entre os pacientes com PCR positiva para M. genitalium, 16,6\% (2/12) apresentaram também resultado positivo para C. trachomatis pelo teste Elisa. No total, C. trachomatis foi detectado em 27,3\% (30/110) das amostras; Neisseria gonorrhoeae, em 5,5\% (6/110); Staphylococcus spp., em 11,8\% (13/110); Streptococcus spp., em 6,4\% (7/110); Escherichia coli, em 1,8\% (2/110); Klebsiella pneumoniae, em 0,9\% (1/110); Enterococcus spp., em 1,8\% (2/110); e Trichomonas spp., em 0,9\% (1/110) das amostras. M. fermentans foi também detectado por PCR com primers específicos em $0,9 \%(1 / 110)$ das amostras de raspado uretral (Figura 1). M. penetrans não foi detectado em amostras deste grupo.

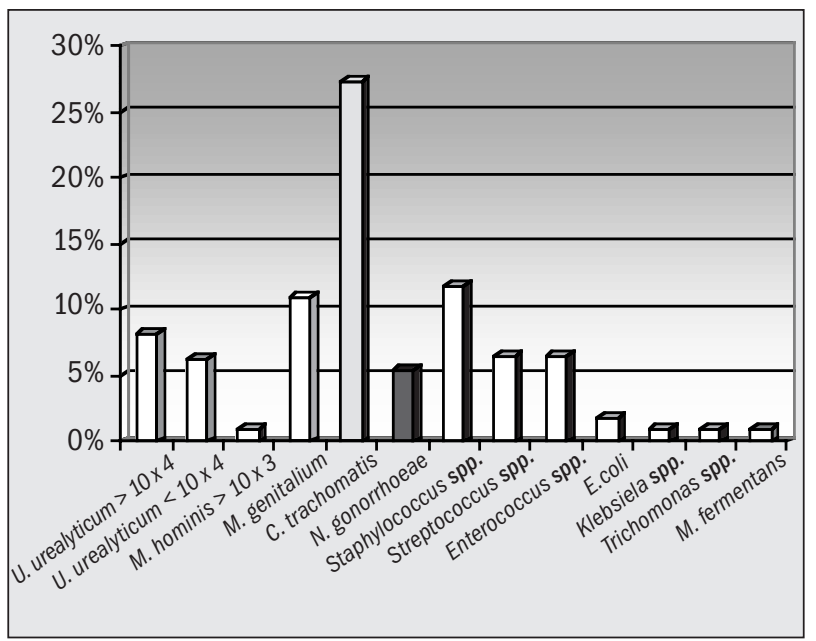

Figura 1 - Porcentagem de microrganismos detectados nas amostras dos pacientes do grupo $A$ (indivíduos com sintomas de uretrite)

\section{Deteç̧ão de micoplasmas nos indivíduos infectados pelo HIV-1}

No grupo de pacientes infectados pelo HIV-1 (grupo B), U. urealyticum foi isolado de $18,9 \%$ (20/106) das amostras, sendo $16,1 \%$ (17/106) em concentrações $\geq 10^{4} \mathrm{CCU} / \mathrm{ml}$ e $2,8 \%(3 / 106)$ em concentrações $<10^{4} \mathrm{CCU} / \mathrm{ml}$. M. hominis foi isolado de $7,5 \%$ (8/106) das amostras, sendo $4,7 \%$ (5/106) em concentrações $\geq 10^{3} \mathrm{CCU} / \mathrm{ml}$, e 2,8\% (3/106) em concentrações $<10^{3} \mathrm{CCU} / \mathrm{ml}$. Assim como no grupo $\mathrm{A}$, não houve diferença nas taxas de isolamento com relação ao tipo de amostra utilizado, seja raspado uretral ou primeiro jato urinário. Quanto à relação entre as taxas de infecção por 
U. urealyticum nos grupos A e B, a diferença observada não é significativa $(p=0,37)$. Por outro lado, considerando a taxa total de infecção por $M$. hominis observada no grupo $B(7,5 \%)$, esta é significativamente maior que a encontrada grupo $\mathrm{A}(0,9 \%)(p=0,02)$.

Através da PCR com o uso de primers genéricos, a detecção de micoplasmas foi positiva em 18,9\% (20/106) das amostras de urina e em 38,7\% (41/106) das amostras de raspado uretral dos pacientes deste grupo. Utilizando primers específicos, M. genitalium foi detectado em 0,9\% $(1 / 106)$ das amostras de urina e em 1,9\% (2/106) das amostras de raspado uretral, sendo estas taxas significativamente menores que as encontradas no grupo $\mathrm{A}$ $(p=0,01)$. M. fermentans foi detectado em $5,7 \%(6 / 106)$ das amostras de raspado uretral neste grupo. Esta taxa é aparentemente maior que a encontrada no grupo $A$, apesar de não ser estatisticamente significativa $(p=0,06)$. $M$. penetrans foi detectado em $6,6 \%(7 / 106)$ das amostras de urina deste grupo, taxa esta significativamente maior que a encontrada no grupo $\mathrm{A}(p=0,006)$. A positividade da detecção das diferentes espécies de micoplasma nos dois grupos estudados está resumida na Figura 2.

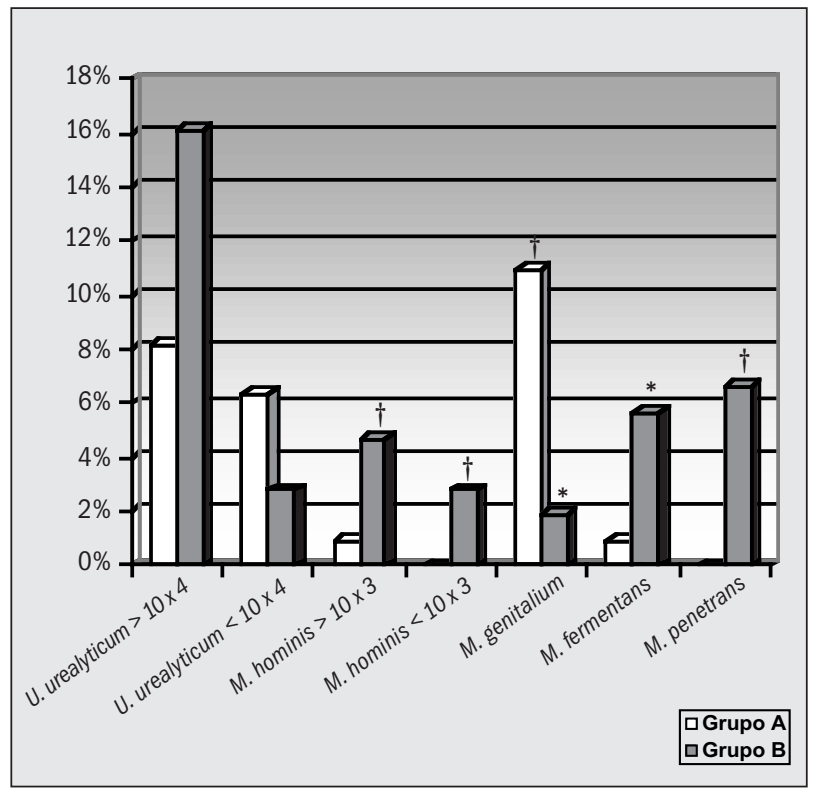

Figura 2 - Comparação dos resultados obtidos na detecção de micoplasmas nos dois grupos estudados, utilizando-se amostras de urina: grupo A (pacientes infectados pelo HIV-1) e grupo B (indivíduos com sintomas de uretrite). *Resultados obtidos com amostras de raspado uretral; tresultados estatisticamente significativos

\section{Discussão}

A prevalência da infecção por micoplasmas em diversos grupos populacionais vem sendo até hoje objeto de estudo de vários grupos de pesquisadores. Atualmente, o papel de $M$. hominis e $U$. urealyticum nas vaginoses bacterianas, e principalmente deste último nas uretrites não-gonocócicas em homens, está bem reconhecido. Entretanto a observação da correlação entre a prevalência dos 14 sorotipos de $U$. urealyticum com diferentes manifestações clínicas e seqüelas de infecção (1), a verificação da diferença de virulência entre estes sorotipos (10), a sugestão da divisão destes sorotipos em duas espécies distintas (U. urealyticum e U. parvum) (21), os casos de infecções extragenitais por estes microrganismos, principalmente em indivíduos imunodeprimidos (28), os crescentes relatos de detecção de resistência dos micoplasmas aos antibacterianos $(5,9)$, e inclusive a descoberta de novas espécies infectando o homem, como $M$. genitalium, $M$. fermentans e $M$. penetrans, vêm continuamente lançando novos desafios na tentativa de estabelecermos a exata participação destes microrganismos na patogenia das doenças humanas. Neste trabalho, pudemos demonstrar uma prevalência importante de micoplasmas urogenitais em dois grupos de pacientes: indivíduos infectados pelo HIV-1 e pacientes com sintomas de uretrite. A detecção das três espécies emergentes de micoplasma merece destaque pelas relevantes taxas de infecção encontradas, em comparação com U. urealyticum e M. hominis. Além disso, sua distribuição entre os dois grupos de pacientes mostrou-se diferente.

A detecção de $M$. penetrans em amostras de indivíduos infectados pelo HIV é mais um indício de sua associação com a doença retroviral. Apesar de sua participação no desenvolvimento da imunodepressão ainda não estar comprovada de maneira definitiva, o fato de esta espécie ser detectada em nossa população, confirmando estudos anteriores $(11,13)$, vem proporcionar bases para que se possam realizar estudos mais aprofundados sobre seu papel na infecção pelo HIV. O fato de M. penetrans ter sido detectado por PCR somente em amostras de urina destes pacientes pode indicar um sítio preferencial de infecção pelo micoplasma, sugerindo que talvez esta espécie habite o trato urinário superior. Entretanto estas observações necessitam de maiores investigações, uma vez que outros autores puderam detectar M. penetrans também em amostras de raspado uretral (11). Além de sua possível implicação na infecção pelo HIV, M. penetrans pode estar também associado a outros tipos de doença, como a síndrome antifosfolipídica primária, cuja etiologia ainda não está bem estabelecida (50). A confirmação da presença, em nossa população, desta espécie de 
micoplasma recentemente descoberta pode abrir novas perspectivas para a investigação de seu envolvimento nas doenças humanas.

Por outro lado, o papel de $M$. fermentans na infecção pelo HIV como co-fator na imunossupressão ainda é incerto, por haver relatos conflitantes sobre sua prevalência em indivíduos infectados pelo HIV-1 e indivíduos HIV-negativos (20). Entretanto a possibilidade de M. fermentans causar acometimentos mais graves, como doenças respiratórias (27) e nefropatias (2), nestes indivíduos merece destaque. Apesar de não ser estatisticamente significativo, pelo baixo número de casos positivos encontrados, em nossa população a taxa de infecção por $M$. fermentans foi maior no grupo de pacientes infectados pelo HIV (grupo B) do que no grupo de pacientes com sintomas de uretrite, sorologicamente HIV-negativos (grupo A). A falta de conhecimento e de recursos laboratoriais na maioria dos serviços para detectar estas infecções não-usuais causadas por micoplasmas provavelmente está dificultando a avaliação de sua real ocorrência.

A prevalência de $M$. genitalium encontrada no grupo de pacientes com sintomas de uretrite por nós estudado foi menor que a relatada previamente por outros autores (43), mas corrobora as evidências de seu potencial em causar uretrite no homem. O fato de, assim como $M$. fermentans, M. genitalium ter sido detectado por PCR somente nas amostras de raspado uretral do grupo A pode indicar também um provável problema de sensibilidade da reação, uma vez que as amostras de raspado foram coletadas antes das amostras de primeiro jato urinário. Nossos resultados indicam que a sensibilidade da PCR com o uso dos primers genéricos inviabiliza sua utilização como triagem das amostras, pois, como observamos, vários pacientes podem ter uma PCR positiva com primers específicos, enquanto a $\mathrm{PCR}$ com os primers genéricos é negativa. Os relatos de envolvimento de $M$. genitalium na etiologia de uretrites não-gonocócicas são inúmeros. Infelizmente, no Brasil, estes dados são praticamente desconhecidos para a grande maioria dos clínicos, e o fato de sua infecção somente poder ser detectada por técnicas de biologia molecular dificulta ainda mais a sua implantação na rotina. Além da uretrite no homem, existe ainda a possibilidade de M. genitalium causar salpingite, por ter sido detectado por PCR no trato genital inferior de $7 \%$ a $20 \%$ das mulheres em consulta numa clínica de doenças sexual- mente transmissíveis (43). Seu envolvimento no trato urogenital superior foi sugerido com base no fato de, in vitro, M. genitalium ter demonstrado capacidade de aderir a células epiteliais das trompas de Falópio, e também ter sido observado um aumento de quatro vezes ou mais no título de anticorpos anti-M. genitalium em um terço de mulheres com doença pélvica inflamatória, por imunofluorescência (29). Estes dados sugerem que, para ser estabelecida tal associação, são necessários maiores estudos. Por outro lado, o simples fato da existência deste tipo de infecção pode ser um fator predisponente para a infecção pelo HIV (32).

O insucesso no isolamento por cultura destas três novas espécies de micoplasma confirma a mesma dificuldade encontrada por vários grupos de pesquisadores. Segundo Jensen et al. (19), somente utilizando uma passagem intermediária com inoculação em cultura de células de amostras positivas por PCR é possível isolar mais facilmente $M$. genitalium a partir de amostras de pacientes com uretrite, contudo esta metodologia é bastante trabalhosa e inviável para aplicação na rotina diagnóstica.

Portanto, concluindo, a detecção das espécies M. penetrans, M. fermentans e M. genitalium, os chamados micoplasmas emergentes, em taxas relevantes em nossa população abre novas perspectivas para o estudo, no Brasil, do envolvimento destes microrganismos nas doenças humanas. Acreditamos que tanto o papel de M. genitalium nas uretrites não-gonocócicas quanto a infecção por $M$. penetrans e $M$. fermentans em indivíduos imunodeprimidos devem ser mais bem considerados. Mesmo a maior taxa de infecção por $M$. hominis no grupo de pacientes infectados pelo HIV pode revelar a possibilidade de esta espécie estar causando infecções mais importantes e mais graves nestes pacientes, conforme discutido previamente (8). Somente a ampliação do conhecimento sobre os tipos de infecção causados pelos micoplasmas e a capacitação dos laboratórios clínicos para a sua detecção são capazes de ajudar a confirmar a associação destes microrganismos com estas manifestações pouco usuais, que podem estar ocorrendo em nosso meio com uma freqüência maior do que se imagina. Ao final, a introdução do diagnóstico de todas as espécies de micoplasma poderá resultar em uma melhora na qualidade de vida destes pacientes. 


\section{Referências}

1. Abele-Horn, M. et al. Association of Ureaplasma urealyticum biovars with clinical outcome for neonates, obstetric patients, and gynecological patients with pelvic inflammatory disease. J. Clin. Microbiol., 35(5): I199-202, 1997.

2.Ainsworth, J.G. et al. Mycoplasma fermentans and HIV-associated nephropathy. J. Infect., 29(3): 323-6, 1994

3. Barbeyrac, B. et al. PCR: preparation of DNA from clinical specimens. In: Tully, J. \& Razin, S. (eds.) Molecular and diagnostic procedures in mycoplasmology. Vol. 2, San Diego: Academic Press, 1996, p. 6I-4,.

4. Bebear, C. et al. New developments in diagnostic and treatment of mycoplasma infections in humans. Wien. Klin. Wochenschr., 109( |4- 15): 594-9, 1997.

5. Bebear, C.M. et al. Mutations in the gyrA, parC, and parE genes associated with fluoroquinolone resistance in clinical isolates of Mycoplasma hominis. Antimicrob.Agents. Chemother., 43(4): 954-6, 1999

6. Blanchard, A. Mycoplasmas and HIV infection, a possible interaction through immune activation. Wien. Klin. Wochenschr., 109(|4-15): 590-3, 1997.

7. Chowdhury, I.H. et al. Mycoplasma can enhance HIV replication in vitro: a possible cofactor responsible for the progression of Aids. Biochem. Biophys. Res. Commun., I 70(3): I365-70, 1990.

8. Cordova, C.M.\& Cunha, R.A. Relevant prevalence of Mycoplasma hominis and Ureaplasma urealyticum serogroups in HIV-I infected men without urethritis symptoms. Rev. Inst. Med. Trop. São Paulo, 42(4): I 85-8, 2000.

9. Cummings, M.C. \& McCormack, W.M. Increase in resistance of Mycoplasma hominis to tetracyclines. Antimicrob. Agents Chemother., 34(12): 2297-9, 1990.

10. Cunha, R.A. et al. Clastogenic effects of different Ureaplasma urealyticum serovars on human chromosomes. Braz.J. Med. Biol. Res., 30(6): 749-57, 1997.

I I. Cunha, R.A. et al. Detection of mycoplasmas in urethral swabs from HIV-I infected patients and control individuals using culture techniques and polymerase chain reaction. Rev. Inst. Med.Trop. São Paulo, 40( I): 1-5, 1998.

12. Dawson, M.S. et al. Detection and isolation of Mycoplasma fermentans from urine of human immunodeficiency virus type I-infected patients. Arch. Pathol. Lab.Med., I I 7(5): 5 | I -4, 1993.

13. Cordova, C.M. et al. Evaluation of IgG, IgM, and IgA antibodies to Mycoplasma penetrans detected by Elisa and immunoblot in HIV-I-infected and STD patients, in São Paulo, Brazil. Microbes. Infect., I (13): 1095-101, 1999.

14. Dussurget, O. \& Roulland-Dussoix, D. Rapid, sensitive PCRbased detection of mycoplasmas in simulated samples of animal sera. Appl. Environ. Microbiol., 60(3): 953-9, 1994.

15. Grau, O. et al. Development of PCR-based assays for the detection of two human mollicute species, Mycoplasma penetrans and M. hominis. Mol. Cell. Probes., 8(2): I39-47, 1994.
16. Grau, O. et al. Association of Mycoplasma penetrans with human immunodeficiency virus infection.J. Infect. Dis., 1 72(3): 672$81,1995$.

17. Grau, $O$. et al. A longitudinal study of seroreactivity against Mycoplasma penetrans in HIV-infected homosexual men: association with disease progression. Aids Res. Hum. Retroviruses., 14(8): 661-7, 1998.

18. lyama, K. et al. Induction of tumor necrosis factor alpha (TNF alpha) and enhancement of HIV-I replication in the J22HL60 cell line by Mycoplasma penetrans. Microbiol. Immunol., 40(12): 907-14, 1996.

19. Jensen, J.S. et al. Isolation of Mycoplasma genitalium strains from the male urethra.J. Clin. Microbiol., 34(2): 286-91, 1996.

20. Katseni, V.L. et al. Mycoplasma fermentans in individuals seropositive and seronegative for HIV-I. Lancet, 34 I (8840): 27I-3, 1993.

21. Kong, F. et al. Phylogenetic analysis of Ureaplasma urealyticumsupport for the establishment of a new species, Ureaplasma parvum. Int. J. Syst. Bacteriol., 49(Pt 4): I879-89, 1999.

22. Lemaitre, $M$. et al. Role of mycoplasma infection in the cytopathic effect induced by human immunodeficiency virus type I in infected cell lines. Infect. Immun., 60(3): 742-8, 1992.

23. Lo, S.C. et al. Identification of Mycoplasma incognitus infection in patients with Aids: an immunohistochemical, in situ hybridization and ultrastructural study. Am.J. Trop. Med. Hyg., $41(5): 601-16,1989$.

24. Lo, S.C. et al. Mycoplasma penetrans sp. nov., from the urogenital tract of patients with Aids. Int. J. Syst. Bacteriol., 42(3): 357 64, 1992.

25. Lo, S.C. et al. Newly discovered mycoplasma isolated from patients infected with HIV. Lancet, 338(8780): | 4| 5-8, I99 |

26. Lo, S.C. et al. Virus-like infectious agent (VLIA) is a novel pathogenic mycoplasma: Mycoplasma incognitus. Am.J.Trop. Med. Hyg., 4 I (5): 586-600, 1989.

27. Lo, S.C. et al. Adult respiratory distress syndrome with or without systemic disease associated with infections due to Mycoplasma fermentans. Clin. Infect. Dis., 17(suppl. I): S259-63, 1993

28. Meyer, R.D. \& Clough, W. Extragenital Mycoplasma hominis infections in adults: emphasis on immunosuppression. Clin. Infect. Dis., 17(suppl. I): S243-9, 1993.

29. Moller, B.R. et al. Serological evidence implicating Mycoplasma genitalium in pelvic inflammatory disease. Lancet, I (8386) | 102-3, 1984

30. Montagnier, L. \& Blanchard, A. Mycoplasmas as cofactors in infection due to the human immunodeficiency virus. Clin. Infect. Dis., I 7(suppl. I): S309- 15, 1993.

31. Nir-Paz, R. et al. Mycoplasmas regulate HIV-LTR-dependent gene expression. FEMS Microbiol. Lett., I 28( I): 63-8, 1995

32. Perez, G. et al. Herpes simplex type II and Mycoplasma genitalium as risk factors for heterosexual HIV transmission: report from the heterosexual HIV transmission study. Int. J. Infect. Dis., 3(1): 5-1।, 1998. 
33. Razin, S. et al. Molecular biology and pathogenicity of mycoplasmas. Microbiol. Mol. Biol. Rev., 62(4): I094- 156, 1998.

34. Ruiter, M. \& Wentholf, H.M.M. The occurrence of a pleuropneumonia-like organism in fuso-spillary infections of the human genital mucosa. Ivest. Dermatol., I 8: 31 3-25, 1952.

35. Saillard, C. et al. Genetic and serologic relatedness between Mycoplasma fermentans strains and a mycoplasma recently identified in tissues of Aids and non-Aids patients. Res. Virol., I 4 I (3): 385-95, 1990.

36. Sasaki, T. et al. Evidence that Lo's mycoplasma (Mycoplasma fermentans incognitus) is not a unique strain among Mycoplasma fermentans strains.J. Clin. Microbiol., 30(9): 243540, 1992.

37. Sasaki, Y. et al. In vitro influence of Mycoplasma penetrans on activation of peripheralT lymphocytes from healthy donors or human immunodeficiency virus-infected individuals. Infect. Immun., 63( I I): 4277-83, 1995.

38. Sasaki, Y. et al. Detection and discrimination of Mycoplasma pneumoniae and Mycoplasma genitalium by the in vitro DNA amplification. Microbiol. Immunol., 36(I): 21-7, 1992.

39. Shepard, M.C. \& Lunceford, C.D. Differential agar medium (A7) for identification of Ureaplasma urealyticum (human $T$ mycoplasmas) in primary cultures of clinical material. J. Clin. Microbiol., 3(6): 613-25, 1976.

40.Taylor-Robinson, D. Diagnosis of sexually transmitted diseases. In:Tully,.. \& Razin, S. (eds.) Molecular and diagnostic procedures in mycoplasmology.Vol. 2, San Diego:Academic Press, 1996, p. 225-36.
41. Taylor-Robinson, D. Infections due to species of Mycoplasma and Ureaplasma: an update. Clin. Infect. Dis., 23(4): 67I-84, 1996.

42.Taylor-Robinson, D. \& Furr, P.M. Genital mycoplasma infections. Wien. Klin. Wochenschr., 109(|4- I5): 578-83, 1997.

43. Taylor-Robinson, D. et al. Occurrence of Mycoplasma genitalium in different populations and its clinical significance. Clin. Infect. Dis., 17 (suppl. I): S66-8, 1993.

44. Tully, J.G. et al. A newly discovered mycoplasma in the human urogenital tract. Lancet, I (8233): |288-91, 1981.

45. Tuppin, P. et al. High prevalence of antibodies to Mycoplasma penetrans in human immunodeficiency virus-seronegative and -seropositive populations in Brazzaville, Congo. Clin. Diagn. Lab. Immunol., 4(6): 787-8, 1997.

46.Van Kuppeveld, F.J. et al. Genus- and species-specific identification of mycoplasmas by $16 \mathrm{~S}$ rRNA amplification. Appl. Environ. Microbiol., 58(8): 2606-15, 1992.

47. Waites, K.B. et al. Cumitech 34, Laboratory diagnosis of mycoplasmal infections. Vol. 34. Nolte, F.S. (ed.) Cumitech, cumulative techniques and procedures in clinical microbiology. Washington D.C.: ASM, 200I.

48. Wang, R.Y. et al. High frequency of antibodies to Mycoplasma penetrans in HIV-infected patients. Lancet, 340(883 I): I 312 6, 1992.

49. Wang, R.Y. et al. Mycoplasma penetrans infection in male homosexuals with Aids: high seroprevalence and association with Kaposi's sarcoma. Clin. Infect. Dis., 17(4): 724-9, 1993.

50. Yanez, A. et al. Mycoplasma penetrans bacteremia and primary antiphospholipid syndrome. Emerg. Infect. Dis., 5(I): 164-7, 1999. 